\title{
Assessing the Microbiological Safety of Raw Meat sold on Different Butcher's Shop in Faisalabad, Pakistan
}

\section{Muhammad Afzaal*, Umber Shehzadi, Rehman Ali, Masood Ahmad, Muhammad Ahtisham Raza, Yasir Abbas Shah and Javeria Mustafa}

Institute of Home and Food Sciences, Government College University Faisalabad, Pakistan

*Corresponding Author: Muhammad Afzaal, Institute of Home and Food Sciences, Government College University Faisalabad, Pakistan.

Received: October 30, 2019; Published: November 12, 2019

DOI: $10.31080 /$ ASNH.2019.03.0543

\begin{abstract}
Microbial contamination and unhygienic conditions make the safety of meat questionable. The aim of this study was to check microbial quality of raw meat samples of chicken, mutton and beef, available on different butcher's shop Faisalabad. Purposely, 30 samples from each road were collected and were examined for microbial contamination. Meat samples of chicken, mutton and beef, were examined for their Coliform, Fecal Coliform count, Salmonella, and Campylobacter according to their standard methods. The result of present study showed that the samples collected from Satyana road and Jhang road were highly contaminated with Coliform (86\%). The sample obtained from Jhang road and Kotwali road had highest Salmonella prevalence (90\%) in chicken. Similarly, Campylobacter was highest in count at Canal road (68.1\%). Sample of all type of meats were contaminated by one or more type of microorganisms. But chicken samples were contained more amount of Salmonella, Coliform and Fecal Coliform than in mutton and beef. Campylobacter was also prevalent in chicken at high level. Result showed that maximum contamination was occurred in chicken collected from Jhang road. Conclusively, it was observed that the microbial contamination is key source of meat spoilage and foodborne illnesses.

Keywords: Raw Meat; Safety; Contamination; Pathogen; Food Borne
\end{abstract}

\section{Introduction}

Food borne pathogens are the major sources of infections and diseases in developing countries. Unhygienic slaughter equipment's and slaughter houses are the main factors that contribute microbial contamination in raw meat [1]. Faisalabad is a large city with more than 3.204 million populations [2]. Raw meat is sold in open air local retail shops without suitable temperature control that is purchased by $50 \%$ households [3]. Meat and meat products are the most important commodities originated from cattle and poultry. They provide an ideal medium for the growth of many micro-organisms due to increased water activity, favourable $\mathrm{pH}$ and higher concentrations of protein, minerals and fermented carbohydrates etc. A few community based out breaks are caused by Salmonella, E.coli, Staphylococcus aureus and Campylobacter in temperature $3^{\circ}{ }^{\circ} \mathrm{C}$. Salmonella in fresh meat especially in poultry causes food infection enteric formation [4]. E. coli, the presence of bacteria in meat and water is the indication of fecal pollution [5]. Staphylococcus aureus commonly found in the mucous membrane of nose and throat is causing the major outbreaks by the consumption of BBQ meat and poultry [6].

Campylobacters are found in reproductive organs, intestinal tract and oral cavity of human and animal. Under favorable conditions may cause diseases [7]. Carcass surface (meat) picks up this micro- organism from intestinal flora during slaughtering process. Yeast and molds play important role in meat spoilage [8] Fungi commonly contaminates meat and its products by causing spoilage by producing mycotoxins which further damages liver and causes liver cancer and food poisoning in human [9]. Microbiological contamination of meat products were being scrutinized intensively during export/import or marketing across the boundaries. This study was conducted to investigate the microbial quality of raw meat available at different butcher's shop of different roads of Faisalabad and examined the hygienic status of meat shops and slaughter houses.

\section{Materials and Methods}

Sample collection

A total 150 samples of fresh raw meat including white and red meat were collected from five local retailer facilities located on main roads of Faisalabad city, Pakistan. A description of samples collected was presented in table $1.25 \mathrm{~g}$ of samples were collected from each road and obtained sample placed in sterilized plastic bags, properly labeled and transferred to the laboratory aseptically. Sample of meat were kept in ice box during transportation to avoid from contamination. Received in laboratory, immediately analyzed for Coliform, Fecal Coliform, Salmonella and Campylobacter according to their standards. Pour plate method was used for isolation and determination of bacteria from raw meat sample [10]. 


\begin{tabular}{|l|c|c|}
\hline \multicolumn{1}{|c|}{ Area } & Sample type & Sample collected \\
\hline Satyana road & Mutton & 10 \\
& Beef & 5 \\
& Chicken & 15 \\
\hline Jhang road & Mutton & 10 \\
& Beef & 10 \\
& Chicken & 10 \\
\hline D ground & Mutton & 12 \\
& Beef & 14 \\
& Chicken & 4 \\
\hline Kotwali road & Mutton & 5 \\
& Beef & 10 \\
& Chicken & 15 \\
\hline Canal road & Mutton & 9 \\
& Beef & 9 \\
& Chicken & 12 \\
\hline & Total samples & 150 \\
& Mutton & 46 \\
& Beef & 48 \\
& Chicken & 56 \\
\hline
\end{tabular}

Table 1: Sample Collection plan for meat samples.

\section{Prevalence of Total Coliform and Fecal Coliform count}

The collected samples were prepared for determination of prevalence of Coliform. A part of meat was cut with sterile knife. $25 \mathrm{~g}$ of meat was put in a sterile mechanical blender and mixed with $225 \mathrm{~mL}$ of sterile buffered peptone water $(0.1 \% \mathrm{w} / \mathrm{v})$. The 10-fold serial dilutions (up to 10-6) were prepared by adding $9 \mathrm{~mL}$ sterile saline solution and $1 \mathrm{~mL}$ homogenized meat sample into the test tubes. The sample was incubated at $35-37^{\circ} \mathrm{C}$ for $24-48$ hours. $0.1 \mathrm{~mL}$ diluted sample from each test tube and poured into petri plates containing MacConkey agar by pour plate method. The MacConkey agar plates were examined for gas and color change. Due to containing phenol red indicator and 1-5 sugar solution, the color of agar change from violet to yellow or effervescence. Most probable number (MPN) of Coliform was calculated on the basis of the proportion of confirmed gassing in MacConkey tubes for 3 consecutive dilutions.15 test tubes was taken having meat samples. The MacConkey broth was added in three sets of five test tubes with the help of sterile pipette, $10 \mathrm{~mL}$ distilled water was added in first set of five test tubes, $1 \mathrm{~mL}$ distilled water in second set of five test tube and $0.1 \mathrm{~mL}$ in third set of five test tube. Tubes were placed in an incubator at $37^{\circ} \mathrm{C}$ for $24-48$ hours. Tubes showing color or volume change were observed. The results of the total Coliform count and Fecal Coliform count were expressed as the number of organism or colony forming units (CFU/g) of meat sample [10].

\section{Prevalence of Salmonella}

Prevalence of Salmonella was tested by adopting spread plate method. $25 \mathrm{~g}$ of blended samples took in a test tubes and test tubes were numbered.10-fold serial dilutions were made, $9 \mathrm{~mL}$ saline solutions were added in test tubes having sample $1 \mathrm{~mL}$. And then tubes were placed in autoclave at $121^{\circ} \mathrm{C}$ for 15 minutes at 15 psi. And $0.1 \mathrm{~mL}$ sample were poured onto nutrient agar plates. The petri plates were incubated at $37^{\circ} \mathrm{C}$ for $24-36 \mathrm{hr}$. Number of colonies was counted. Test was used to check the prevalence of Salmonella [11].

\section{Prevalence of Campylobacter}

$25 \mathrm{~g}$ of meat sample was blender in a stomacher machine and added sterile buffered peptone water $(0.1 \%)$ about $225 \mathrm{~mL}$ and homogenized it. $1 \mathrm{~mL}$ of homogenized sample was inoculated in a test tube having $9 \mathrm{~mL}$ of distilled water. $0.1 \mathrm{~mL}$ Diluted sample was taken and poured into petri plates having blood agar. Sample was spread into the plates. The sample was incubated at $48^{\circ} \mathrm{C}$ for $24-48$ hours in an incubator. Number of colonies was counted. Test was used to check the prevalence of Campylobacter [12].

\section{Results and Discussion}

Most probable number (MPN) was used to observe total Coliform and Fecal Coliform count. All the observed samples were very high with total Coliform and Fecal Coliform. 10 mutton, 5 beef and 15 chicken samples were taken from Satyana road. Coliform and Fecal Coliform detected in mutton, beef and chicken was $80 \%$, $80 \%$, and $86 \%$ respectively. From Jhang road, 10 mutton, 10 beef and 10 chicken samples were brought. Observed Coliform and $\mathrm{Fe}$ cal Coliform in mutton, beef and chicken were contaminated 70\%, $80 \%$ and $90 \% .12$ mutton, 4 beef and 14 chicken samples were collected from the place of D-ground. And all these samples were contaminated with Coliform and Fecal Coliform 83.3\%, 75\% and $85 \%$ severally. 5 mutton, 15 beef, and 10 chicken samples were obtained from Kotwali road. Coliform examined in these samples were $60 \%, 66.6 \%$ and $70 \%$ respectively. 12 mutton, 9 beef and 9 chicken samples were collected from the place of canal road. Coliform and Fecal Coliform discovered in mutton, beef and chicken was $66.6 \%, 66.6 \%$,and $77.7 \%$ severally [13]. The result regarding Coliform and Fecal Coliform are present in table 2. The data showed that maximum prevalence was observed in sample collected from Jhang road. The type of sample showed that chicken was contaminated more.

The prevalence of Salmonella in raw meat procured from popular roads of Faisalabad has been shown in table 3. The result showed that maximum prevalence was in samples collected from Jhang road and the type of sample showed that maximum contamination was occurred in chicken. Observed the most samples were contaminated with Salmonella. At Satyana road, chicken was contaminated with Salmonella about 53.3\%. Mutton, beef and chicken were contaminated with Salmonella about $40 \%, 60 \%$ and $90 \%$ at Jhang road [14]. From the place of D-ground, chicken was highly contaminated. Samples collected from Kotwali road, in which beef was highly prevalent with Salmonella. At Canal road mutton, beef 


\begin{tabular}{|l|c|c|c|c|}
\hline \multicolumn{1}{|c|}{ Area } & Type of Sample & No. of samples & + ive & \% Age Value \\
\hline Satyana & Mutton & 10 & 8 & $80 \%$ \\
road & Beef & 5 & 4 & $80 \%$ \\
& Chicken & 15 & 13 & $86 \%$ \\
\hline Jhang & Mutton & 10 & 7 & $70 \%$ \\
road & Beef & 10 & 8 & $80 \%$ \\
& Chicken & 10 & 9 & $90 \%$ \\
\hline D- & Mutton & 12 & 10 & $83.3 \%$ \\
ground & Beef & 4 & 3 & $75 \%$ \\
& Chicken & 14 & 12 & $85 \%$ \\
\hline Kotwali & Mutton & 5 & 3 & $60 \%$ \\
road & Beef & 15 & 10 & $66.6 \%$ \\
& Chicken & 10 & 7 & $70 \%$ \\
\hline Canal & Mutton & 12 & 8 & $66.6 \%$ \\
road & Beef & 9 & 6 & $66.6 \%$ \\
& Chicken & 9 & 7 & $77.7 \%$ \\
\hline
\end{tabular}

Table 2: Prevelance of Coliform and Fecal Coliform in meat sample.

\begin{tabular}{|l|c|c|c|c|}
\hline \multicolumn{1}{|c|}{ Area } & Type of Sample & No. of sample & ${ }_{+i i} \mathbf{v e}$ & \% Age value \\
\hline Satyana & Mutton & 10 & 3 & $30 \%$ \\
road & Beef & 5 & 1 & $20 \%$ \\
& Chicken & 15 & 8 & $53.3 \%$ \\
\hline Jhang & Mutton & 10 & 4 & $40 \%$ \\
road & Beef & 10 & 6 & $60 \%$ \\
& Chicken & 10 & 9 & $90 \%$ \\
\hline D & Mutton & 12 & 7 & $58.3 \%$ \\
ground & Beef & 4 & 3 & $75 \%$ \\
& Chicken & 14 & 11 & $78.5 \%$ \\
\hline Ko twali & Mutton & 5 & 2 & $40 \%$ \\
road & Beef & 15 & 6 & $93.3 \%$ \\
& Chicken & 10 & 5 & $70 \%$ \\
\hline Canal & Mutton & 12 & 6 & $50 \%$ \\
road & Beef & 9 & 5 & $55.55 \%$ \\
& Chicken & 9 & 6 & $66.6 \%$ \\
\hline
\end{tabular}

Table 3: Prevalence of Salmonella in meat samples.

and chicken was examined and chicken was prevalent with Salmonella. From all evaluation, chicken was highly contaminated with Salmonella from Jhang road [15].

Similarly, Campylobacter was also detected in raw meat. Results regarding Campylobacter are present in table 4. The data showed that maximum prevalence was observed in sample collected from canal road. Examination of those samples showed that Campylobacter is mostly present in chicken. At Satyana road,10 mutton samples, 5 beef samples and 15 chicken samples were brought. In which Campylobacter was detected in mutton, beef, chicken 60\%, $60 \%$, and $80 \%$. Samples collected from Jhang road, 10 samples of mutton, 10 of beef and 10 of chicken were collected which observed $70 \%$ 40\% and 80\% Campylobacter. From D-ground, 12 mutton, 4 beef and 14chicken samples were procured and analyzed 50\%, $25 \%$ and $42 \%$ contamination. From Kotwali road samples were collected of 5 mutton, 15 beef and 10 chickens. and Campylobacter was examined $60 \%, 53 \%$ and $70 \%$ in raw meat. At canal road 12 mutton, 9 beef and 9 chicken samples were collected for examined. Campylobacter was more observed in chicken about 88.8\% [16]. The study revealed that raw meat samples were highly contami- nated with several harmful microorganisms and pathogens which cause serious sickness including GIT diseases. Different studies were also carried out for analysis of raw meat and its safety standards. In one study, we have to notice that $86 \%$ raw meat is contaminated with microorganism and pathogens. In another study, similar result was obtained and $96 \%$ Coliforms were contaminated the raw meat.

\begin{tabular}{|l|c|c|c|c|}
\hline \multicolumn{1}{|c|}{ Area } & Type of Sample & No. of samples & +ive & \%age \\
\hline Satyana road & Mutton & 10 & 6 & $60 \%$ \\
& Beef & 5 & 3 & $60 \%$ \\
& Chicken & 15 & 12 & $80 \%$ \\
\hline Jhang road & Mutton & 10 & 7 & $70 \%$ \\
& Beef & 10 & 4 & $40 \%$ \\
& Chicken & 10 & 8 & $80 \%$ \\
\hline D ground & Mutton & 12 & 7 & $50 \%$ \\
& Beef & 4 & 1 & $25 \%$ \\
& Chicken & 14 & 6 & $42 \%$ \\
\hline Kot wali & Mutton & 5 & 3 & $60 \%$ \\
road & Beef & 15 & 8 & $53.3 \%$ \\
& Chicken & 10 & 7 & $70 \%$ \\
\hline Canal road & Mutton & 12 & 9 & $75 \%$ \\
& Beef & 9 & 6 & $66.6 \%$ \\
& Chicken & 9 & 8 & $88.8 \%$ \\
\hline
\end{tabular}

Table 4: Prevalence of Campylobacter in meat samples.

\section{Conclusion}

The existing study revealed the microbial contaminated raw meat is being sold at butcher's shops at popular roads of Faisalabad in Pakistan. The prevalence of Salmonella was higher as compared to others like Campylobacter, Coliform in raw meat. Chicken have highly microbial load than beef and mutton. It might be due to poor sanitary environment of the slaughtering place and poor personal hygiene of the workers handling the meat. It is especially important to provide training to meat handlers regarding food safety.

\section{Bibliography}

1. Kim JH., et al. "Monitoring of Microbial Contaminants of Beef, Pork, and Chicken in HACCP Implemented Meat Processing Plants of Korea". Korean Journal for Food Science of Animal Resources 38.2 (2018): 282.

2. Ali NH., et al. "Microbial contamination of raw meat and its environment in retail shops in Karachi, Pakistan". The Journal of Infection in Developing Countries 4.06 (2010): 382-388.

3. Hussain AO. "Isolation and diagnosis of some pathogenic bacterial species contamination from red meat in shops and markets in Thi-Qar city". Journal of College of Education for Pure Science 8.2 (2018): 226-236.

4. Zwe YH., et al. "Prevalence, sequence types, antibiotic resistance and, gyrA mutations of Salmonella isolated from retail fresh chicken meat in Singapore". Food control 90 (2018): 233240. 
5. Aslan A., et al. "Presence of antibiotic-resistant Escherichia coli in wastewater treatment plant effluents utilized as water reuse for irrigation". Water 10.6 (2018): 805.

6. Cuny C., et al. "Nasal Colonization of Humans with Occupational Exposure to Raw Meat and to Raw Meat Products with Methicillin-Susceptible and Methicillin-Resistant Staphylococcus aureus". Toxins 11.4 (2019): 190.

7. Sałamaszyńska-Guz A., et al. "Evaluation of selected phenotypic features among Campylobacter sp. strains of animal origin". Veterinary microbiology 21.6 (2018): 25-30.

8. Zakki SA., et al. "Microbial quality evaluation and prevalence of bacteria and fungus in different varieties of chicken meat in Lahore". RADS Journal of Pharmacy and Pharmaceutical Sciences 5.1 (2017): 30-37.

9. Iheshivlor MOO., et al. "Effect of mycotoxin in animal nutrition”. Asian Journal of Animal Sciences 5.1 (2011): 19-33.

10. Zafar A., et al. "Microbiological Evaluation of Raw Meat Products Available in Local Markets of Karachi, Pakistan". Pakistan Academy of Sciences B. Life and Environmental Sciences 53.2 (2016): 103-109.

11. Arshad F and Zahoor T. "Assessing the microbiological safety status of most commonly consumed food items sold at local and branded restaurants of Faisalabad, Pakistan". Journal of Food Safety 39.1 (2019): e12587.

12. Nisar M., et al. "Occurrence of Campylobacter in retail meat in Lahore, Pakistan”. Acta Tropical 18.5 (2018): 42-45.

13. Odwar JA., et al. "A cross-sectional study on the microbiological quality and safety of raw chicken meats sold in Nairobi, Kenya". BMC Research Notes 7.1 (2014): 627.

14. Waghamare RN., et al. "Studies on occurrence of invasive Salmonella spp. from unorganised poultry farm to retail chicken meat shops in Mumbai city, India". International Journal of Current Microbiology and Applied Sciences 6.5 (2017): 630-641.

15. Cabedo LL., et al. "Prevalence of Listeria monocytogenes and Salmonella in ready-to-eat food in Catalonia, Spain". Journal of Food Protection 71.4 (2008): 855-859.

16. Sharma KP., et al. "Prevalence of campylobacter species in raw meat samples sold in open market of Kolkata city". International Journal of Agriculture, Environment and Biotechnology 9.4 (2016): 535-539.

\section{Volume 3 Issue 12 December 2019}

(C) All rights are reserved by Muhammad Afzaal., et al. 